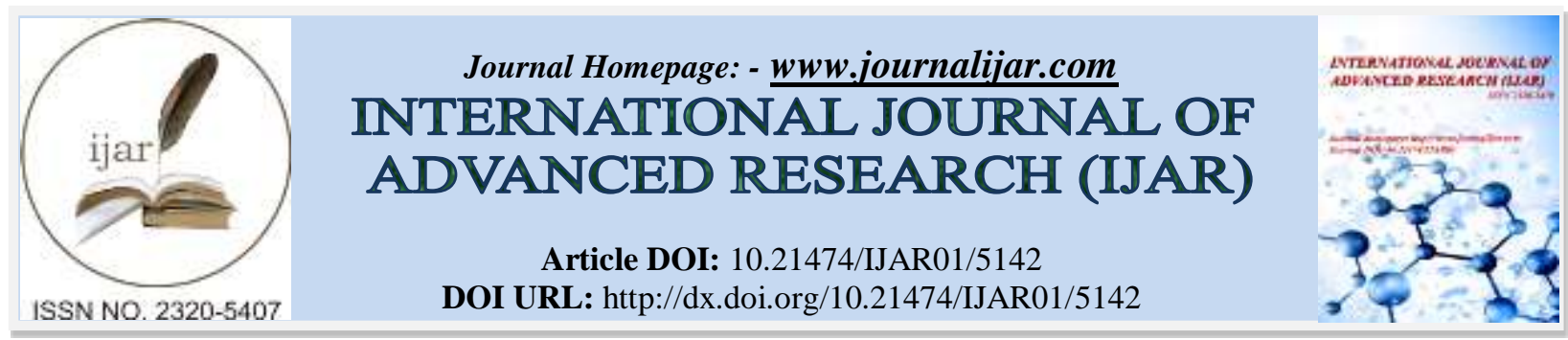

RESEARCH ARTICLE

\title{
EXPELLING THE SPIRIT OF NITER: THE DIFFERENTIAL DIAGNOSIS AND TREATMENT OF A YOUNG MALE WITH NON-SUICIDAL SELF-INJURY BEHAVIOR AND PSYCHOSIS.
}

Dr. Asma Salman Albaiz.

M.D., Psychiatry Senior registrar. Prince Sultan Military Medical City, PSMMC, Riyadh, Saudi Arabia.

\section{Manuscript Info}

Manuscript History

Received: 11 June 2017

Final Accepted: 13 July 2017

Published: August 2017

Key words:-

Self-mutilation, Non-suicidal Self-injury

(NSSI), Depression, Psychosis, Bipolar.

\section{Abstract}

Background: Self-mutilation, or non-suicidal self-injury (NSSI), is defined as when a person consciously commits injury to their own body. NSSI is associated with depression, borderline personality disorder, and other psychiatric conditions. NSSI has been included in the revised DSM-5 as a unique condition in its own right, occurring often during the teenage and adolescent years, and sometimes in later life. Continuation of such a cycle of self-mutilation becomes dangerous with time and leads to an increased risk of suicidal feelings. The prevalence rate in males and females by the teenage years is $6: 1$, decreasing with age to reach $3: 1$ or 4:1 by the second decade of life.

Case presentation: This case study is of a young man who presented with persecutory delusions and bizarre complaints, following longstanding low mood. He believed that he was possessed. He was fixed on harming himself by burning his body. He had attempted suicide more than once, and had homicidal ideas of killing his wife and son. In addition, he had visual and auditory hallucinations. Though depression was initially assumed, the progression of his symptoms resulted in a diagnosis of Bipolar disorder type II.

Copy Right, IJAR, 2017,. All rights reserved.

\section{Introduction:-}

As he walked into the Emergency Room everybody stared at him. The scars and fresh wounds all over his face and body made it look as though he had been badly burned in several accidents. However, he had not been involved in any injurious accidents! He was also not known to suffer with any illnesses, and he had never even witnessed a fire.

Non-suicidal self-injury (NSSI), self-inflicted violence, deliberate self-harm, or self-mutilation is defined as when a person consciously and intentionally commits injury to their own body causing damage and inducing marks over a period of time. This is carried out to cope with a difficult or distressing situation without any conscious suicidal intent (1). Many research studies have demonstrated that NSSI has occurred in individuals for a long time prior to such abnormal behavior starting to be understood. Medical interventions have eased the condition over the years. Nevertheless, there exists a further need for new controlled studies to ensure that patients suffering from selfmutilation disorder continue to receive effective therapy (2). Self-mutilation could be a pathological disorder; Favazza and Rosenthal reviewed article data from more than 250 articles and books, as well as information gathered from the experience of psychiatrists in managing self-mutilation. The authors categorized self-mutilation into three different types: the major-infrequent type that causes significant tissue damage, usually with acute intoxications and psychosis; stereotypic-fixed, rhythmic behavior, mostly occurring with mental retardation; and superficial or 
moderate-behavior (for example, burning, skin cutting, and scratching) occurring alongside different psychiatric disorders (3). In another publication, Favazza concluded by stating that, "Although no one approach adequately solves the riddle of such behaviors, habitual self-mutilation may best be thought of as a purposeful, if morbid, act of self-help" (4).

Self-mutilation was considered to be an abnormal behavior, rather than a mental illness that pointed towards poor coping skills. However, NSSI has been observed to be usually accompanied by symptoms of other psychiatric disorders. Most commonly it is considered to be a symptom of borderline personality disorder (BPD), but it is not unique to sufferers of BPD. NSSI is also seen to occur alongside dissociative disorders, as well as many other Axis I disorders, including major depressive disorder, generalized anxiety disorders, substance abuse, and eating disorders. There has also been preliminary support for the independence of NSSI as a unique disorder, distinct from BPD (5). Since April 2017, NSSI has been included in the revised Diagnostic and Statistical Manual of Mental Disorders $5^{\text {th }}$ edition (DSM-5) as a unique condition for additional investigation (6).

Self-mutilation often occurs during the teenage and adolescent years, and sometimes later in life. People who have experienced trauma, neglect, or abuse are at most risk of this behavior type, as are substance users. An individual who does not know how to deal with anger, frustration, or painful emotions may use self-harm as a release. This is supported by the physiological principle that pain stimulates endorphin release, thus raising mood. In contrast, when in a state of emotional numbness, someone might induce pain in order to create some real feelings in place of that numbness. However, a self-mutilated person experiences shame and guilt after committing self-harm. Such guilty feelings exaggerate negative feelings, leading to the provocation of another self-harming cycle. Hence, a "vicious circle" of self-harm is established. Continuation of such a self-mutilation cycle becomes dangerous over time and increases the risk of suicidal feelings (7).

The DSM-5 criterion for diagnosing NSSI is as follows: repeatedly, for at least five days of the year, the individual has deliberately self-mutilated leading to damage to the body of a sort likely to provoke bleeding or pain (e.g., cutting, stabbing, hitting, excessive rubbing), with the assumption that the injury will not cause death. Males and females prevalence rates of NSSI are thought to be closer to each other than for suicidal behavior disorder, in which the female-to-male ratio is about $3: 1$ or $4: 1$ (8).

When mood elements combine with psychosis, self-mutilation, personality changes, conversion episodes, and suicidal attempts, diagnosis becomes an enigma, which requires accurate resolution. The accurate taking of a patient's history and continuous observation of the patient is, therefore, required. Here, we describe an illustration of a challenging case of a young male who presented with bizarre behavior and self-harm. This was manifested as the burning of his face and body with acidic water (spirit of niter), and him claiming that it was caused by a demon. The subject also was experiencing auditory and visual hallucinations, persecutory delusions, and a long-standing history of low mood, which was difficult to diagnose, but suggested the possibility of major depressive disorder with psychotic features.

\section{Case-Presentation:-}

The subject was a 24 year-old male, who had been married for two years, had one healthy male child aged 10 months, and who worked in an administrative job. He was in his usual state of health until two years prior to this time, when he got married and moved to another city, following which he started to have difficulty falling asleep and to experience disturbed sleep with frequent awakenings and nightmares. In the main, he could not sleep for more than 5 hours and he would wake up very tired; he remained in bed for hours with low mood and had no interest in starting his day. He reported some history of frequent and inexplicable crying, isolation from others, a decrease in appetite, poor hygiene, and a general and significant decrease in interest in life. His symptoms progressed to the point of him considering his life both boring and not worth living, accompanied by having death wishes.

Some psychotic symptoms started to manifest. He was suspicious that everyone did not like him, and whenever he saw people laughing, he always thought that they were laughing at him. He started to skip work, because he thought that his colleagues did not like him and they were saying that he was crazy. The subject reported that he had once seen his wife caring for his baby, and he started to hear more than one male and female voice talking to him and saying things such as, "your wife does not like you and she is trying to put poison in your food." These symptoms lasted for five months before the subject presented. Unfortunately, the subject did not seek help during the more preliminary stages of the illness. 
Upon interviewing the subject, he relayed his disturbed behavior and crying spells and put them down to the presence of a "female jinni" inside him who was telling him to buy acid water (nitric acid - aqua fortis - spirit of niter) and commanding him to burn himself with it. He could not resist these voices and always responded to her orders. The subject said, "she will kill me if I do not burn myself." For that reason, he poured acid several times on his face, chest, hands, and other parts of his body. He had multiple scars and wounds due to self-mutilation (deliberate self-harm), and the wounds have sharp edges, which suggested use of a knife. When confronted, he admitted to using a pen that he dipped in nitric acid water and applied to his skin. He also stated that these acts were attention seeking, and that at the same time he gained a feeling of pleasure from the pain, and claimed he acted impulsively.

The subject's wife reported observing him having bouts of gradual muscle spasms with anxiety and fear lasting for five minutes when the patient became angry, but without any loss of consciousness or rhythmic contractions. A possible diagnosis of Conversion Disorder was made at this stage. Unfortunately, the subject bought poison and cooked it with food for his wife and son, and told her about it saying, "It's an eye for an eye," as he accused her of trying to poison him. In addition, the "female jinni" inside him ordered him to kill his wife, as she is in love with him, which increased his frustration and precipitated two suicide attempts with the plan to throw himself off a bridge. That was between 3-4 months beforehand. He had actually been to the bridge twice, contemplating the idea of jumping, but when he remembered his family, he regretted his thoughts and returned home. His wife then brought him to the emergency room where he was seen for the first time by a psychiatrist, who diagnosed him with major depressive disorder with psychosis.

The subject was not known to have any previous medical conditions. His vital signs at the hospital interviews showed normal readings. Physical examinations were all normal, including the neurological exam. His laboratory investigations, including urinary toxicology showed normal (negative toxicology) results, and he denied having any current suicidal ideation.

An antidepressant ( $25 \mathrm{mg}$ of Paroxetine, taken before sleep) was prescribed, in addition to instructions for behavioral techniques to improve his coping with stressors, and psycho-education and reassurance. There was also short-term follow-up at the out-patients' clinic for the subject and his family. A week later, he attended his first appointment with the psychiatry clinic. Here, he reported an appreciable degree of improvement in mood and sleep and good compliance with his medication. The subject continued to be seen as an out-patient every two weeks. A month after from his first visit, the "female jinni" and his self-harming behavior were significantly improved and had almost disappeared. At this time, the dose of Paroxetine was increased to $50 \mathrm{mg}$ daily in order to enhance the subject's response and to maintain the outcome.

Although the subject was committed to taking his medication, two months later he reported a relapse and the "female jinni" was talking to him again. Associated with his relapse, the subject described some conflicts at home and some difficulties in finding a suitable place to live. Hence, $50 \mathrm{mg}$ Haloperidol daily was added, but resulted in a poor response as, two weeks later, the subject attempted suicide. This suicide attempt was planned and he had texted his wife to say farewell and to tell her that he was about to commit suicide. The wife sent some of his friends to bring him home. The next day, the subject came to hospital by himself and a decision to admit him was made. The subject was kept in the hospital for two weeks. The Minnesota Multiphasic Personality Inventory was carried out to rule out any personality disorders, and the results were negative. During the first week, the subject was unmedicated, but he seemed active, over-familiar, talkative and had a reduced need for sleep. Bipolar Type II Disorder was added to the board and 500mg Valproic acid was initiated. The subject showed significant improvements thereafter, becoming more stable, calmer and sleeping normal hours, with no abnormal behavior observed. A computer tomography scan and electroencephalograph were performed, producing normal reports. A decision to discharge him home on Valproic acid alone was made, and he attended a short-term follow-up psychiatric clinic two weeks later. The subject presented to the clinic with a great degree of improvement. He described a valuable improvement in the amount of sleep he was getting, his ability to concentrate, and the decrease in conversion symptoms. The follow-ups with the subject were extended to a monthly basis. The overall outcome with medication for bipolar disorder has been reassuring, and up to the time of writing, the patient still attends follow-ups at the outpatient psychiatry clinic. 


\section{Conclusion:-}

The case study reports a young man experiencing persecutory delusions and bizarre complaints, after a longestablished low mood, at the first psychiatric interview. The patient complained that, "I have a jinni inside me" and "she wants me to burn myself." He believed he was possessed, and became fixated on harming himself by burning his face and body. He had a suicidal attempt and homicidal ideas of killing his wife and son. He also had visual and auditory hallucinations, which were difficult to diagnose, but suggested the possibility of major depressive disorder with psychotic features. We made the assumption that the man was depressed and treated him for it. However, as a result of this treatment, he became temporarily manic, but finally recovered completely. After his recovery, he was diagnosed as suffering from a Bipolar type II Disorder. The lack of typical symptoms of mania and the remarkable self-injury in this patient made it difficult to infer a state of bipolar disorder. Nevertheless, having knowledge of his strange familiarity and his sleep pattern would have helped us to make an accurate diagnosis earlier.

\section{Discussion:-}

Self-mutilation is known to be more common in females than in males (3:1 or in some studies even 4:1). The most common mental disorder associated with self-mutilation is borderline personality disorder, for which the female gender again makes up the majority of patients (75\%) (8). Having a self-mutilating male patient also presenting with bizarre symptoms makes this case significant, and worthy of sharing within the clinical psychiatry community. Selfmutilating behavior might start at a young age: 12 years old or younger. However, in this age group, the female prevalence is as high as 6.3:1 in comparison to males. Fortunately, this age group is the most responsive to treatment (9). Our subject is a 24-year-old who married at the age of 22 years old. In this age group in Saudi Arabia, the majority of the male population are unmarried, as they have just graduated from college, or they are beginning to establish their adult life. Although finding a 24-year-old male who is married with a child in Saudi Arabia is quite rare, there is an exception within some tribal customs and traditions. Is it possible that this could have a negative effect on this subject by putting relatively big responsibilities on him at a young age?

One of the mental illnesses most closely related to self-mutilation is depression, as mentioned in introduction. Seeing a patient with poor sleep, poor appetite, loss of interest in life, and low mood, with inexplicable crying, moved the diagnosis towards depression, and this was supported by the history of suicide attempts. Although his scars due to self-mutilation required investigation and treatment more than other symptoms and signs, the start of antidepressant medication was inevitable initially, and the patient's response encouraged the treating psychiatrist to emphasize major depression disorder as the primary mental diagnosis. The subject was treated as an out-patient to begin with due to his fairly stable condition at interview. He was thinking rationally, had no suicidal ideation, a negative urine toxicology result, and a family member was present with awareness of the subject's mental status. A research study published in June 2017 reported data collected on more than 16,000 self-mutilators during an eightyear follow-up period. There was found to be no difference between patients treated in hospital or as out-patients followed up in clinics (10). Carroll, et al. found an increase in self-mutilation in hospitalized patients (11). In fact, self-mutilating patients need to be assessed for a requirement of in-hospital monitoring regardless of the type of mental illness or the method of self-harm utilized.

This subject was suffering from a mixed type of delusions. He thought no one liked him at work, although his productivity at work was stable. Persecutory delusions were playing a further role with respect to his wife. He thought that she had tried to kill him, while in fact she was always with him at the hospital and tried to help. DSM-5 can lead to possible misdiagnosis of patients as having a major depressive disorder with psychosis, while presentation with persecutory delusions might be a sign of dissociative identity disorder (DID) (8). Our subject's family denied any symptoms of DID, as did the subject himself.

While Yadav et al. published a study stating that poison is the most common method used by self-mutilators, $88 \%$ of the study group did not plan before committing self-mutilation (12). Birtwistle et al. published a large center cohort study stating that self-poison represents $72 \%$ of 10,829 episodes of self-mutilation, using data from 6155 patients. A combination of self-mutilation methods represents only $7 \%$, but suicide occurred more frequently in this group in comparison to mutilators who solely used poison (13). Self-mutilators have a greater risk of committing suicide in comparison to the general population. The American Journal of Psychiatry published a recent article (14) reporting that the rate of repeat self-mutilation is 263.2 per 1,000 person-years during the 12 months following initial selfmutilation. The rate of successful suicide was 439.1 per 100,000 person-years, 37.2 times greater than in the general population. The peak time for suicidal attempts was during the first 30 days following initial violations of self- 
mutilation $(\mathrm{HR}=17.5,95 \% \mathrm{CI}=11.2-27.3)$. The group of mutilators by firearms $(\mathrm{HR}=15.86,95 \% \mathrm{CI}=10.7-23.4)$ were the most at risk, and there was a minimal risk amongst patients who received outpatient mental health care $(\mathrm{HR}=1.6,95 \% \mathrm{CI}=1.2-2.0)$. In this study, the patient reported homicidal attempts against his wife and child using poisons.

The initial prescription of anti-depressants was justifiable due to the subject's overall symptoms and his good response within a short-time. For that reason, the continuation of the anti-depressant course was not doubted by the clinician. However, the subject's relapse was questioned, and no clear reason was identified for it, except for social stressors due to his family situation, especially house-hunting. We did not hesitate in admitting the patient to hospital for further observations and management, especially after the further suicide attempt. Interestingly, we observed a manic period during the course of his stay in hospital. That made it necessary to stabilize his mood with Valproic acid. Our decision to use this drug was based on well-established guidelines and studies that support it as a first-class mood stabilizer. The side-effects of lithium treatment are unbearable, especially in the Saudi Arabian climate, and Valproic acid was observed to be effective for this subject.

Finally, we excluded any other causes of self-mutilation from our diagnosis, and ascertained that our subject was not suffering from any substance-induced mental illness.

\section{References:-}

1. Plante LG: Bleeding to ease the pain: Cutting, self-injury, and the adolescent search for self. Greenwood Publishing Group, 2007.

2. Simpson C: Self-mutilation. Greensboro, NC: ERIC Clearinghouse on Counseling and Student Services, 2001 Dec.

3. Favazza AR, Rosenthal RJ: Diagnostic issues in self-mutilation. Psychiatric Services 1993 Feb; $44(2): 134-40$.

4. Favazza AR: Why patients mutilate themselves. Psychiatric Services 1989 Feb; 40(2):137-45.

5. Zetterqvist M: The DSM-5 diagnosis of nonsuicidal self-injury disorder: a review of the empirical literature. Child and Adolescent Psychiatry and Mental Health 2015 Sep 28; 9(1):31.

6. Victor SE, Davis T, Klonsky ED: Descriptive characteristics and initial psychometric properties of the NonSuicidal Self-Injury Disorder Scale. Archives of Suicide Research 2017 Apr 3; 21(2):265-78.

7. Self-harm | NAMI: National Alliance on Mental Illness [Internet]. Nami.org. 2017. Available from: https://www.nami.org/Learn-More/Mental-Health-Conditions/Related-Conditions/Self-harm.

8. American Psychiatric Association: Diagnostic and statistical manual of mental disorders (DSM-5®). American Psychiatric Pub, 2013 May 22.

9. Diggins E, Kelley R, Cottrell D, House A, Owens D: Age-related differences in self-harm presentations and subsequent management of adolescents and young adults at the emergency department. Journal of Affective Disorders 2017 Jan 15; 208:399-405.

10. Steeg S, Emsley R, Carr M, Cooper J, Kapur N: Routine hospital management of self-harm and risk of further self-harm: propensity score analysis using record-based cohort data. Psychological Medicine 2017 Jun; 1-2.

11. Carroll R, Corcoran P, Griffin E, Perry I, Arensman E, Gunnell D, et al: Variation between hospitals in inpatient admission practices for self-harm patients and its impact on repeat presentation. Social Psychiatry and Psychiatric Epidemiology 2016; 51(11):1485-1493.

12. Yadav AK, Rai BK, Bhandari R, Shakya DR, Gupta PP, Moore M, Budhathoki SS: Methods used and reasons for deliberate self harm: A cross-sectional study in acute care setting of Eastern Nepal. Health Renaissance 2017 Jun 20; 13(2):92-104.

13. Birtwistle J, Kelley R, House A, Owens D: Combination of self-harm methods and fatal and non-fatal repetition: A cohort study. Journal of Affective Disorders 2017 Aug 15; 218:188-94.

14. Olfson M, Wall M, Wang S, Crystal S, Gerhard T, Blanco C: Suicide Following Deliberate Self-Harm. American Journal of Psychiatry 2017 Mar 21; appi-jp. 
Appendix:-
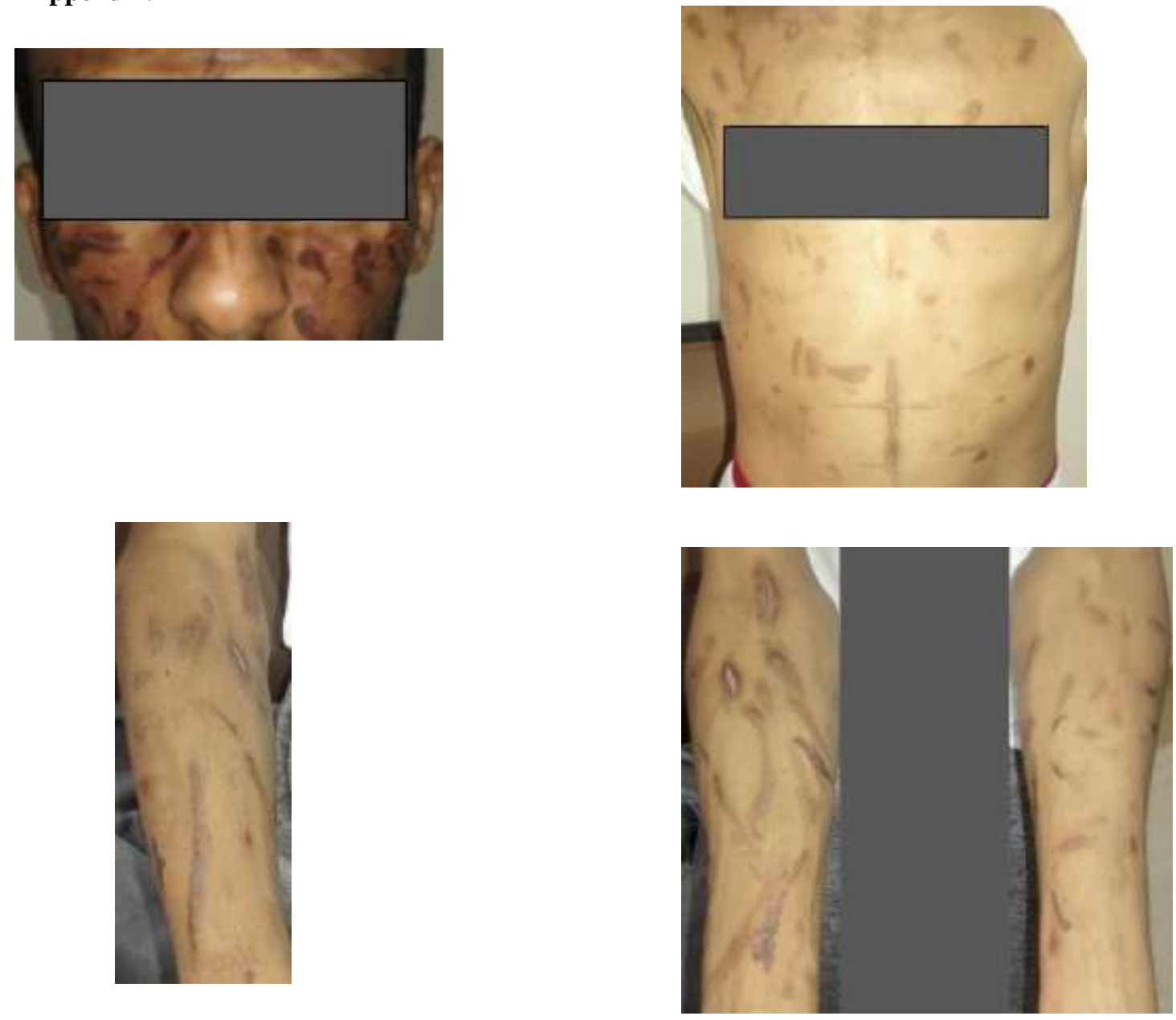